\title{
Review of the Molecule of the Month Website in 1997
}

\author{
Paul May \\ School of Chemistry, University of Bristol, Bristol BS8 1TS, U.K. \\ Tel. +44 (0)1179289000 x4276 (internal x4276); Fax +44 (0)117 925 1295; E-mail: paul.may@ bristol.ac.uk
}

Received: 12 December 1997 / Accepted: 14 January 1998 / Published: 25 January 1998

\begin{abstract}
This review describes the history of the "Molecule of the Month" Website, along with a short summary of some of the molecules which featured during 1997.
\end{abstract}

Keywords: Molecule of the Month, WWW, review

\section{Introduction}

The Molecule of the Month website [1,2] is based at the University of Bristol in the UK, and as well as being a site containing many interesting chemical facts, is also a good example of the way the web can be used to create a truly worldwide database of information. Each month this page features a few paragraphs of information about a particular molecule, written in a way that's both interesting, informative, as well as being understandable to people with only a basic knowledge of chemistry (e.g. science undergraduates). The page can originate from an industrial lab, university chemistry department, or even a science journalist, and can reside anywhere in the world that's connected to the web. Over the past 2 years the list of featured molecules has built into quite a useful archive of chemical data, and has highlighted both recent advances in chemistry as well as in the technology of the web.

\section{History}

The Molecule of the Month page [1] came about as a result of chance remark sent to the chemistry webmasters mailing-list. In November 1996 someone posted that it would be a good idea if there was an electronic version of the 'Molecule of the Week' page that appeared in the Science column of the Daily Telegraph newspaper. Most people thought it sounded like a fun idea, and so I and a few others, such as Henry Rzepa from Imperial College London [3] and Karl Harrison from Oxford [4], decided to try and make it a reality, in the form of Molecule of the Month (MOTM) pages. We each chose different strategies for our pages. Henry's MOTM pages are all written by himself and highlight work he, his colleagues, or his molecular modelling group have performed recently. Karl's pages are also written by himself, and as well as having pages about specific molecules, he also widens the brief slightly to include collections of similar molecules and themed molecules (e.g. gemstones or vitamins).

I decided upon a different approach. When Tim Berners Lee from Cern invented the web about 5 years ago, the vision was of a distributed information database, with parts of the information stored in different locations all over the world. To be true to this idea, I decided that my MOTM pages would be written by many different authors from as many countries and types of establishment as possible. I would only be responsible for maintaining the index of hyperlinks pointing to the various pages, as well as deciding which of the submitted pages became that month's MOTM. 
So the Bristol MOTM page began in January 1996, with a contribution from Henry Rzepa of mauveine, the molecule that initiated the dye industry. As 1996 continued, we managed to persuade more people to volunteer some of their time to create MOTMs, and had molecules as diverse as aspirin, ferrocene, and even water! 1996 also saw great advances in the technology of the web, most notably for chemistry with the introduction of the Chime plug-in [5] for Netscape, and the java-based Chemsymphony [6]. Both these advances allowed 3dimensional structure information of molecules to be displayed and manipulated in real-time on a web page. This allowed the MOTM pages to become visually quite stunning, with rotating molecules in stick or spacefill modes decorating the pages. The drawback was that not everyone has the appropriate plug-in or java-aware browsers necessary to see these 'enhanced' pages. The answer was to have several different versions of the pages, so the reader could choose which page they wished to view.

\section{Some of the Molecules}

In this article, I intend to give a brief description of some of the molecules that have featured in the MOTM's second year, 1997. These molecules have spanned a wide range of chemical activities, from synthetic organic chemistry and biochemistry, to crystallography, organometallic chemistry, and even theoretical chemistry!

\section{$C_{60}$}

1997 began with the molecule $\mathrm{C}_{60}$ - an appropriate choice since the Nobel prize for Chemistry had been won only a few months earlier for studies of that very molecule (Figure 1). The contribution came from an ex-member of the fullerene group at Sussex University, which is where Harry Kroto did some of the pioneering work in this area. The page contains a very nice history of the discovery of buckminsterfullerene, as well as a number of Chime models which clearly show the structure of the bonding within the molecule. There is even a version of $\mathrm{C}_{60}$ in VRML format, for those of you that wish to 'fly through' a buckyball!

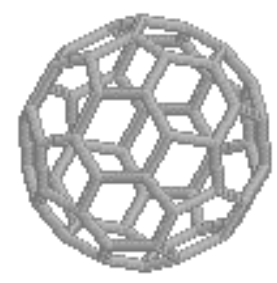

A buckyball
Taxol

Taxol (Figure 2) was the MOTM for February, submitted by a postdoctoral worker in the organic chemistry department at Bristol. This is a very important anti-cancer drug, and the page gives its full structure, as well as the history of its discovery, and a detailed synthetic route to making it in the laboratory. The page is full of interesting facts about the molecule, such as: The natural source of taxol, the Pacific yew tree, is an environmentally protected species, which is also one of the slowest growing trees in the world. Isolation of the compound, which is contained in the bark, involves killing the tree, and the quantities available by this method are pitifully small. It would take six 100-year old trees to provide enough taxol to treat just one patient!

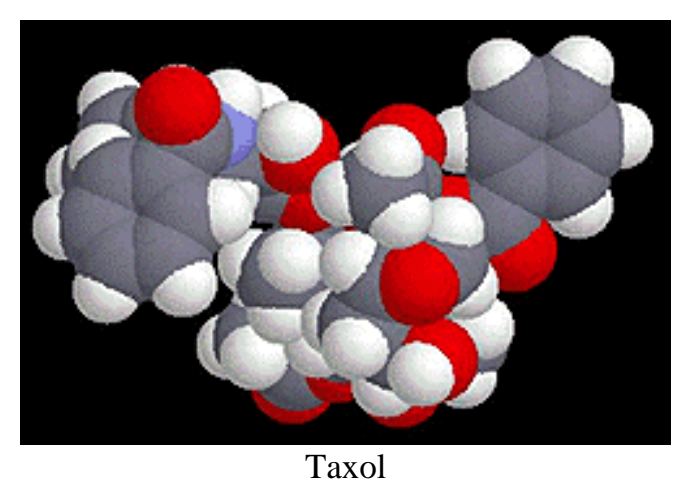

Figure 2.

$t-\mathrm{AlF}_{3}$

March's MOTM was t- $\mathrm{AlF}_{3}$ (Figure 3) and is situated at the University of Lemans in France. The molecule itself is interesting mainly for its unusual structure rather than its properties. $\mathrm{t}-\mathrm{AlF}_{3}$ is a new allotropic form of aluminium trifluoride, and represents the ninth recently discovered $\mathrm{AB}_{3}$ framework of $\mathrm{AB}_{6}$ octahedra connected exclusively by corners. Its structure was never predicted, and it was only discovered by chance during a neutron diffraction study of hydrated $\mathrm{AlF}_{3}$.

This page contains numerous Chime structures and VRML fly-throughs of many related structures and crystallographic building blocks.

Figure 1. 


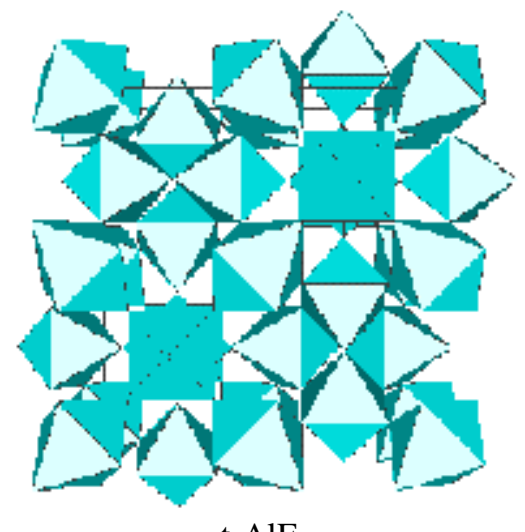

$\mathrm{t}-\mathrm{AlF}_{3}$

Figure 3.

\section{Hexol}

Hexol was September's MOTM, and was the first to be situated at a Jamaican University (Univeristy of Mona, West Indies). Hexol (a shorthand for the organometallic compound $\left.\left[\mathrm{Co}\left(\mathrm{NH}_{3}\right)_{4} \mathrm{CO}_{3}\right]_{2}\right)$, is important because it can be thought of as the beginning of modern co-ordination chemistry. Its discoverer, Alfred Werner, who obtained the Nobel prize for this, went on the realise that optical isomers of inorganic compounds were possible and so laid the foundations for much of today's inorganic chemistry. Continuing the theme of pushing the boundaries of technology, this MOTM page contains IR, UV and visible spectra of hexol and related molecules, presented in JCAMP format. This allows the spectra to be manipulated in real time using the Chime plug-in, so that the user can obtain $x-y$ co-ordinates of spectral lines, zoom in and out, etc.

\section{4-Bromo-4'-Methoxyacetophenone Azine}

The last MOTM for 1997 was provided by the University of Missouri, and was an organic ferroelectric material called 4-Bromo-4'-Methoxyacetophenone Azine (Figure 5). This material is unusual in that it forms a crystal structure in which each layer contains perfectly dipole-parallel aligned azines and the dipole moments of the layers reinforce each other to produce a near-perfectly dipole-aligned ferroelectric material. The page contains nice Chime structures of the molecule itself, as well as a structure for the crystal packing.

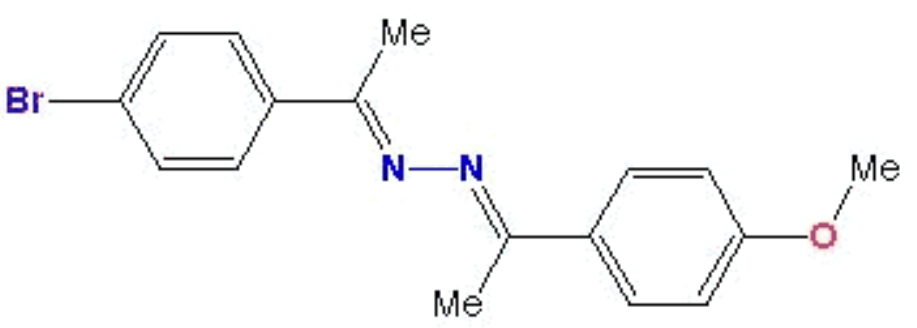

4-Bromo-4'-Methoxyacetophenone Azine

Figure 5.

\section{Outlook and Concluding Remarks}

In this article I've only had chance to highlight a few of the 12 MOTMs that appeared last year. There are another 7 which are equally worthy of note, and I would encourage you to peruse the page for the others.

As 1998 approaches, the MOTM page continues to flourish, with a new molecule being added every month. A new MOTM page typically gets 500 hits for the first month, which drops down to about 200 hits per month from then on. This is quite good publicity for the website in question, and is therefore one of the incentives that inspires people to volunteer a page. The current waiting list is only about 3 months, so if you feel you'd like to contribute a MOTM, please email me with your suggestion. You can write about any molecule you like, so long as it's interesting and understandable by an undergraduate chemist. It can be a molecule you have worked on personally, or one that just takes your fancy. The MOTM page continues only so long as the enthusiasm persists among those who contribute - so get writing!

Figure 4. 


\section{References and Notes}

1. Molecule of the Month at Bristol - http://www.bris.ac.uk/Depts/Chemistry/MOTM/motm.htm

2. My Home Page - http://www.bris.ac.uk/Depts/Chemistry/staff/pwm.htm and email address (paul.may@bris.ac.uk)

3. MOTM page at Imperial College London - http://www.ch.ic.ac.uk/motm/, administered by Henry Rzepa http://www.ch.ic.ac.uk/rzepa/

4. MOTM page at Oxford - http://www.chem.ox.ac.uk/mom/ administered by Karl Harrison http://www.chem.ox.ac.uk/it/karlharrison.html

5. MDLI site for the Chemscape Chime plug-in - http://www.mdli.com/chemscape/

6. Cherwell Scientific, home of Chemsymphony - http://www.cherwell.com/chemsymphony/index.html 